\title{
Mitchiner Memorial Lecture, 1986: The Surgeon's Oldest Enemy
}

\author{
Miles Irving, \\ MD, ChM, FRCS Professor of Surgery \\ University of Manchester, Honorary Consultant Surgeon, Hope Hospital, Salford
}

I am conscious of the honour bestowed upon me by this invitation to give the Mitchiner Lecture. In many ways I am a different lecturer from those before me who have been similarly honoured. Most of them had some connection, albeit often tenuous, with Mitchiner. I cannot claim any such connection as, when I arrived upon this earth, he was already well advanced in his profession having been appointed to the Staff of St. Thomas' Hospital that same year. However, he was not without influence upon me for, like many others of my generation, I dipped into Romanis and Mitchiner in the course of my pre-Fellowship reading.

Although the title of my talk does not give a clear indication of its subject I am sure that many will have formulated their own ideas. To some the subject will be physicians, to others administrators and to yet others it will be the nursing hierarchy, for you will have recalled the words of Sir Ian Fraser in his third Mitchiner Lecture:

"his (Mitchiner's) rapier . . . seemed always
unsheathed and ready for senior generals, consultant
physicians, field marshals or matrons, but never for
subalterns, the house surgeon or the British soldier"l.

Happily the days of serious professional confrontation appear to have passed and, although rivalry between specialties remains, the vast expansion of medical knowledge means that team work and interdisciplinary co-operation are now a necessity for the successful practice of medicine.

I think that all who are involved with surgery will agree that of the many factors, which from time immemorial have upset our best endeavours, bacterial infection has always been, and remains, our principal adversary.

Mitchiner wrote on the problems of bacterial infection as seen by a surgeon of his time $e^{2.3 .4}$. Yet, when one looks at these papers they describe problems that spontaneously have almost disappeared. How often do those of us in surgical practise today see the carbuncles and awful mid-palmar and thenar space infections which occupied so much of our time twenty-five years ago? On the other hand postoperative and post-traumatic infection have certainly not disappeared. Despite antibiotics and modern supportive therapy, uncontrolled abdominal sepsis appears as malign today as in Hunter's graphic description of an officer dying of peritonitis following a bullet wound of his abdomen ${ }^{5}$ : "about three hours after receiving this wound, I saw him with Mr Grant. He was pretty quiet, not in much pain, rather low, pulse not quick, nor full and a sleepy languidness in the eye, which made me suspect something more than a common wound. He then had neither a stool nor made water. . . We saw him again at three o'clock (8 hours after injury). He was now rather lower, pulse smaller, more restless, a good deal of tension in the belly which made him uneasy ... on patting the belly especially along the course of the transverse arch of the colon, it plainly gave the sound and vibration of air. ... We saw him again at nine o'clock in the evening. His pulse was now low and more frequent; coldness at times; vomiting veryळ frequent . . .; the belly very tense . . . we began to suspect that it was becoming paralytic. ..."

Hunter's patient died at 7.00 am the next day from generalised bacterial peritonitis, shown by post mortem examination to be the result of duodenal and colonic perforation. Of course today he would have had 2 laparotomy and the defects closed, but if the suture lines leaked a very similar picture to that described by Hunte? would have ensued.

In this lecture I want to look at the problems posed by? abdominal sepsis today and to suggest that some of the difficulties we face result from forgetting the lessons that have been learned by previous generations of surgeons. Sadly, in this respect we are repeating the sins of our forbears. It is well recognised, particularly in war surgery, that they repeatedly forgot the importance of delayed primary suture in the treatment of missile injuries.

It is thus worth looking back briefly at the problems faced by our predecessors to see how they dealt with the task of treating the injured in a manner that would prevent the onset of sepsis. Although they did not know the cause of infection, they recognised it as almost invariably culminating in death.

Few lessons emerged before the Middle Ages simply because battles were often so violent that most injured soldiers did not live long enough to develop complications. Thus in the battle of Cannae (216 BC) 50,000 Roman soldiers were killed in a day. It was with the advent of firearms that one began to see damage to limbs which, though often gross, was not immediately fatal. It was the management of these injuries that taxed the minds of such famous surgeons as Ambrose Paré (1510 
1590). His major contribution was to recognise that agonising procedures such as the application of boiling oil or the cautery, previously advocated as a means of preventing sepsis, did more harm than good. His replacement of this treatment by dressings moistened with a mixture of oil of roses and turpentine not only saved soldiers from much pain but also prevented the production of yet further dead tissue in the wounds.

The famous hero and surgeon of the Napoleonic wars, Dominique-Jean Larrey (1766-1842) was another who advanced the management of wounds sustained in battle. Initially he was an advocate of early amputation for gunshot wounds of the extremities, actually ablating 200 limbs in 24 hours during the battle of Borodino on the road to Moscow. Although this zealous activity was considered as "operative mania" by the Edinburgh military surgeon Blackadder, the $75 \%$ survival rate is commendable especially in the era prior to the teachings of Lister and Pasteur.

Undoubtedly Larrey continued to practice the technique of debridement taught him by his mentor Desoult. Larrey was well aware of the consequences of inadequate treatment of wounds and of the onset of sepsis, and was one of the first to describe the complication of "pouriturre des hopitaux" known otherwise as hospital gangrene. Larrey's other contribution was in supportive care of the injured. Although he did not invent the ambulance he was the first to organise an ambulance service which brought patient and surgeon together more rapidly and efficiently than before, a development which then, and subsequently, has been shown to be a major factor in improving survival.

It is clear that soldiers did survive serious injuries in the days before antibiotics and the application of Listerian principles, even when the quality of the surgeons left much to be desired. It is acknowledged that in the American Civil War (1861-1865) some of the medical services were less than ideal, yet, in that war, of 58,702 people injured in the extremeties, only 2366 died $^{6}$.

In some ways these figures reveal a moderately satisfactory situation. In those circumstances where injured soldiers received good local wound care supported by general measures such as limb splinting, careful transport and possibly good nutrition, the outlook was usually favourable. However, overall the picture was bleak especially in hospitals, where death from infection was the usual outcome of surgical operation.

It was into this scene that Lister (in 1867) introduced his principles of antiseptic surgery. The result was dramatic with lethal postoperative infection becoming the exception rather than the rule. Yet, without wishing to decry the undoubted value of Lister's work I believe the introduction of his ideas actually may have led to a worsening of the results in war injuries, probably due to a reduction in the standard of wound care. The story of gas gangrene is illustrative. It is noteworthy that Hunter did not describe gas gangrene. He surely would have done so most graphically had he come across it. Similarly 3 it was not recorded in the Crimean War or the American $\mathbb{\Omega}$ Civil War. A few instances were reported in the Franco- $O$ German War of 1870 but nothing to compare with the huge numbers seen in the early part of the 1914-18 war, $\stackrel{?}{9}$ especially in the retreat from Mons, the first battle of Ypres and at the Somme ${ }^{7}$. However by 1917 and $1918 \frac{?}{7}$ the incidence had begun to fall with only 84 cases in $\frac{C}{0}$ 25,000 injured patients. Whilst it cannot be denied that $\frac{\bar{\omega}}{\bar{\omega}}$ the soil on which these battles took place was the source $\vec{\nabla}$ of the clostridial infection, why within one war was there $\varrho$ both a sudden increase and a subsequent decline in this $\$$ lethal infection? Was it because of an inappropriate use $\vec{\circ}$ of Lister's principles? Perhaps, for Bowlby', in his Hunterian Oration, concluded that the reason for the $\vec{\omega}$ reduction in incidence was due to

". . . the abandonment of strong antiseptics and to the timely excision and surgical cleansing of the wound and the removal of all foreign bodies".

Mitchiner also made the same point ${ }^{8}$. Writing in the Practitioner in 1939 on the topic of immediate surgery $\frac{\mathrm{m}}{\mathrm{O}} \mathrm{O}$ air raids he commented

“As a general rule antiseptics find little or no place $\rightarrow$ the surgical treatment of wounds . . . it must obvious that any antiseptic used in sufficient streng to kill or even inhibit the growth of organisms in severely lacerated wound must of necessity have deleterious effect on the gravely damaged tissue io and around the wound".

It is interesting to note the reference to the implief dangers of strong antiseptics. Were they the equivalent of the boiling oil of Parés time? Once again the prime importance of good wound care had to be emphasised.

In World War II the situation was different because of $\overrightarrow{\overrightarrow{0}}$ the availability of sulphonamides and penicillin. There $\exists$ can be little doubt that these drugs saved many lives. Yet I suspect that in this war too undue reliance was placed, by some, upon these agents and that as a result local $\exists$ wound care deteriorated. Why else should Lt General L D Heaton, the Surgeon General of the Department of the Army have commented in the $1960 \mathrm{~J}$ M T Finney $\vec{\Phi}$ Fund lecture: ${ }^{9}$

"The sulfonamides, and penicillin after it became available, played an important part in these results: but it was the understanding application of the principles of thorough debridement and delayed primary wound closure - both developed in World 9 War I - that conquered the greatest deterrent to $\square$ successful traumatic surgery; that is wound infection"?

Strange grammar and punctuation, but the message is $N$ clear! 
And so to the latest war involving this country. Tho figures from the Falklands campaign reflect enormous credit on our young military surgeons. Yet even today, with all our powerful antibiotics and modern supportive techniques infection still occurred (Table 1). In reflecting on the approach to treatment of battle injuries Surgeon Commander R J Leicester stated ${ }^{10}-$

"We followed the example set to us by the surgeons during the Second World War, and we had the advantage of starting out with penicillin. But if you ignore the principles of good surgery, then even penicillin will not prevent the complications".

So, in the relative calm of British society today, where few of us see firearm injuries of trunk or limb, do the findings of previous generations of military surgeons have any relevance in our day-to-day general surgical practise? I believe the answer is certainly "Yes". No one denies that antibiotics can be lifesaving in those with systemic infections, with septicaemia, and in spreading cellulitis. Similarly one cannot deny the evidence showing that high dose peri-operative antibiotics are effective in preventing infections in high risk surgery such as that on the large bowel. However I believe that there is much inappropriate antibiotic usage, especially in the treatment of focal sepsis within the abdomen. In these circumstances antibiotics may be as harmful as the boiling oil mentioned by Paré and the strong antiseptics mentioned by Bowlby, simply because they may direct attention away from the need to excise dead tissue. Additionally they frequently lead to the emergence of resistant bacteria and the associated lethal superinfections.

What is the extent of the problem of abdominal sepsis today? There is a wide variation between what is obtainable and everyday reality in most centres. Krukowski working with Matheson in Aberdeen ${ }^{11}$ reported a series of 1504 abdominal operations in a 5 year period with only a $2.8 \%$ wound infection rate and an $0.8 \%$ intraperitoneal sepsis rate. Their techniques are simple and reproducible and thus there is no doubt that their figures should be the gold standard against which the rest of us should measure our performance. Sadly other series from the United Kingdom do not report such low levels ${ }^{12,13}$.

Such infections not only carry with them danger to life, but cause extraordinary expense to the Health Service. It is thus our duty to prevent infection by all possible means. However, even with the best techniques and the most potent prophylaxis, wound infections and intra-abdominal sepsis still occur. How should we deal with them when they arise?

Aeberhart and Casey in their excellent monograph ${ }^{14}$ show the distribution of abdominal sepsis in a collected series of cases (Table 2) and also how lethal it can be. The least problematic abdominal sepsis to deal with is wound infection. Antibiotics are rarely of value unless there is surrounding cellulitis and I cannot think of any
Table I

Postoperative Infection in the Falklands War
225 Analysed Casualties
133 Operations
37 Postoperative Infections

(Figures by Courtesy of Surgeon Commander E P Dewar, FRCS, RN)

better instructions for the management of this problem than those of Hunter $^{5}$

"It will generally be necessary to open them by art, whether they have opened of themselves or not; for the natural opening will seldom be sufficient for the complete cure; and although it may be sufficient for the free discharge of the matter, yet they will heal more readily if sufficiently opened;"

Table 2

\begin{tabular}{ll}
\hline \multicolumn{1}{c}{ Postoperative Intra-Abdominal Sepsis } \\
\hline \multicolumn{1}{c}{ 135 Patients (1975-1979) } \\
Intra and Retroperitoneal Abscess
\end{tabular}

Wounds that do not respond immediately to this treatment and continue to produce a purulent discharge should be reassessed. Sometimes there is an undrained loculus of pus, in other cases there is a fistulous communication with the gastroinestinal tract. In those cases in which the patient is also extremely unwell and the tissues surrounding the wound are dying then a diagnosis of necrotising fasciitis should be considered. In such circumstances there is now no doubt that the correct treatment is radical surgical excision of the dead tissue. Delays occasioned by intensive antibiotic treatment or hyperbaric oxygen serve only to risk the patient's life. The treatment that will save the patient is radical excision of the dead tissue (Figures 1,2 ). The extent of the required excision may sometimes be dramatic but the resulting defects granulate well. In those cases where viscera are exposed, evisceration can be prevented by the use of Marlex mesh.

The problem with intra-abdominal sepsis is greater for, of necessity, the dead and infected tissue is often "locked in" by the abdominal wall. The problem of how to deal with the dead tissue is taxing indeed for it is not easy to excise it in the manner I have described for the 
abdominal wall. Additionally there is the added difficulty of dealing with extensions of purulent material that pass along anatomical pathways (Figure 3). Most abdominal sepsis comes from spontaneous or postoperative leakage from the gastrointestinal tract. It must be a priority to stop this leakage if it is continuing in an uncontrolled fashion. There is little doubt in my mind that if, at re-operation upon a leaking anastomosis, there is a breakdown of the suture line and the patient is septic and hypoalbuminaemic then the only safe course of action is to take down the anastomosis and exteriorisc both ends. Of course such patients are not immune from the problems of residual sepsis and others present with intra-abdominal sepsis. How do we assess such cases? We are fortunate today in having a whole range of investigations to assist us. However, we should not be so anxious to use these that we forget to examine the patient. The site of many abscesses in the abdomen can be determined by abdominal palpation and pelvic examination. However, even if we can feel the abscess, few of us would now fail to call upon our radiological colleagues for help, not only because they can use sinography, ultrasound, indium leucocyte scanning and, most useful of all, CAT scanning to show the site of an abscess; they can also treat some of them. The radiologist's ability to aspirate abscesses is now of proven value, and in my experience has virtually eliminated the need for surgical intervention in subphrenic abscesses. However, not all intra-abdominal abscesses are suitable for this form of treatment, especially when they are multiocular or contain thick necrotic material. How should such patients be treated?

Much interest was raised by Hudspeth ${ }^{15}$ in his paper advocating radical peritoneal debridement for the treatment of advanced generalised bacterial peritonitis.

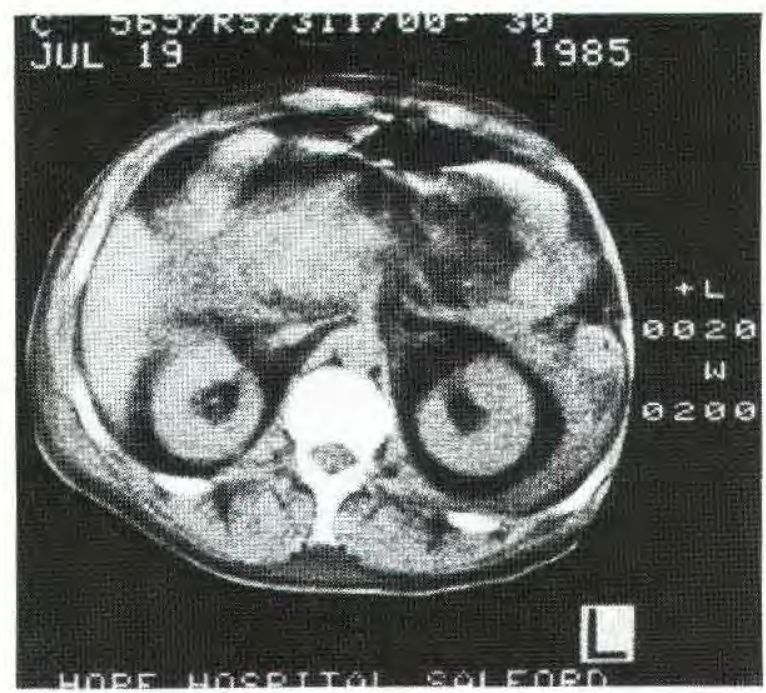

Fig 3. CAT scan showing extension of pancreatic abscess around both kidneys.
However I believe that Hudspeth was misusing the term debridement, which implies the removal of dead and devitalised tissue. The fibrinous exudates he included in his excision do not fit into this category which is probably why Polk in a subsequent more realistic controlled study could not reproduce the results ${ }^{16}$.

I believe that true abdominal debridement does have a place, especially in the patient with repeated postoperative sepsis, necrotising pancreatitis and pancreatic abscess. One way of achieving this is by the technique known as "laparostomy", originally described by the French surgeon Fagniez ${ }^{17}$. Our own experience in this technique has been, on the whole, rewarding ${ }^{18}$. The access it provides to the deeper recesses of the retroperitoneum enables them to be cleaned of pus and necrotic tissue without the need for re-operation (Figure 4). Our figures of $28 \%$ survival in intractable intraabdominal sepsis generally, and $46 \%$ in cases of pancreatic abscesses specifically ${ }^{19}$ are better than most others dealing with the problems of a similar severity. Yet I remain unhappy with this technique for it is undoubtedly traumatic for the patient and time consuming for the nursing staff. In this respect I am intrigued by the developments taking place in the se Antoine Hospital in Paris where Etienne Levy and hise colleagues are treating abdominal sepsis with drains that appear to mc to give the advantages of laparostomy typ $\bar{\Theta}$ access into the deeper recesses of the intra-abdomini abscess in combination with the undoubted advantage of abdominal wall closure (Figure 5$)^{20}$. Future studie will allow assessment of whether or not these drains produce results equivalent to laparostomy. For sucg studies to be conclusive it must be shown that the cas treated by the different methods are comparable. se many studies in the past, including our own, have been anecdotal and uncontrolled.

The first step in moving towards a practical system of grading sepsis was made by Professor H B Stoner of the MRC Trauma Unit and Professor E A Elcbute from Lagos during the course of a visiting Professorship in my department. Their scoring system uses the patients lesions, such as abscesses and fistulae, the pattern of pyrexia and the concentration of blood constituents such as albumin, platelets, leucocytes, together with signs of organ failure to give a sepsis score, ranging from zero to the mid thirtics ${ }^{2 \Gamma}$. A persistent score of 20 or over carries a poor prognosis. Already the score has been used to study the metabolic changes that occur with differing degrees of sepsis.

Much as I have advocated improvement in the local surgical management of abdominal sepsis I also have to emphasise the importance of the metabolic care of the septic patient.

It has been recognised for many years that the patient with uncontrolled sepsis loses wcight due to a combination of inadequate food intake and the catabolic ơ effects of infection (Figure 6). Few would disagree with the premise that the fastest and most effective way to

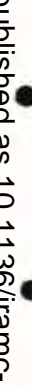

W




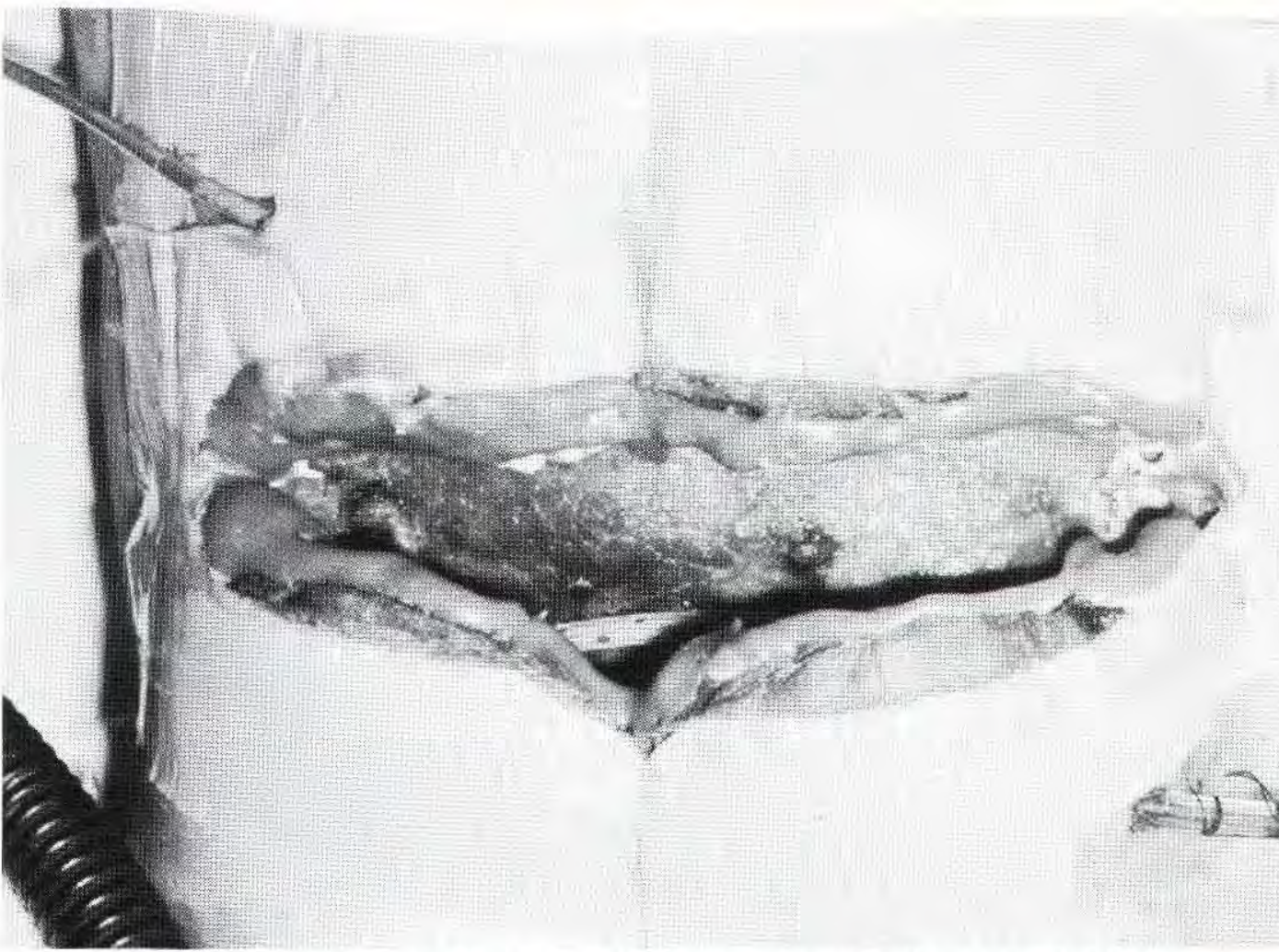

Fig 4. Laparostomy wound allowing access to recesses and exten sion of intra-abdominal abscess.

reverse this situation is to eliminate the sepsis. However, as I have shown this can be a time consuming process, and whilst it is taking place the patient will need nutritional support. In the majority this can be provided through the gastrointestinal tract but in others, particularly those with fistulae, parenteral nutrition may be necessary.

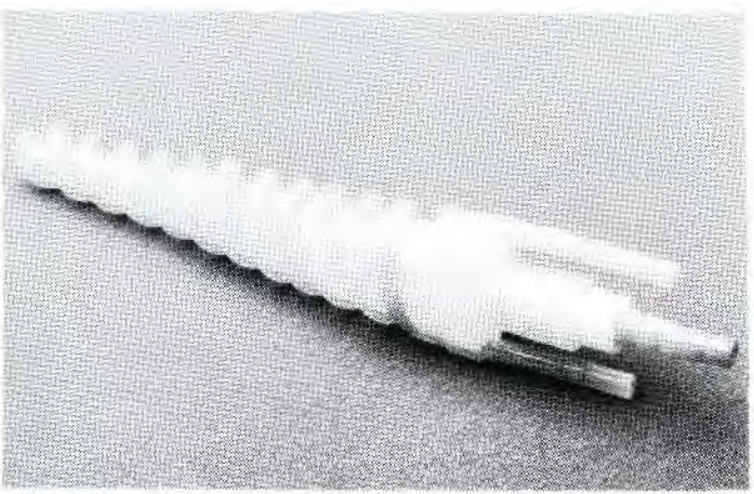

Fig 5 . Conical silastomer drain used by Levy and his colleagues for treatment of intra-abdominal sepsis.
I have been fortunate to work in collaboration wit many excellent young scientists on the staff of the MR Trauma Unit at Hope Hospital. With their collaboration we have been able to explore the energy demands of the septic patient and also to investigate the substrates being used by these patients.

Our first endeavours demonstrated that the basal energy expenditure of the septic patient was much less than had been previously supposed. Indeed rarely did this exceed $2000 \mathrm{KCals}$ and was usually much less. The previous efforts to provide these patients with 5000 $6000 \mathrm{KCals}$ were clearly inappropriate.

In a series of experiments using indirect calorimetry we were able to demonstrate that fat is the main fuel used by the grossly septic patient ${ }^{22}$. We showed that glucose oxidation was negatively, and fat oxidation positively, related to the severity of sepsis even in patients receiving glucose in significant quantities ${ }^{23}$. Further assessment of this phenomenon has been undertaken using the hyperglycaemic glucose clamp technique. After an overnight fast, the plasma glucose concentration is raised to $12 \mathrm{mmol} /$ litres by glucose infusion and kept at this level for 2 hours. Plasma glucose is measured at frequent intervals and the glucose infusion rate adjusted to keep the plasma level steady.

\section{○ 잉

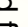 훅 ถุ․․ 올 O
D
O
$\bar{N}$
N
N
N
N}


We have shown that control paticnts, that is individuals without any sepsis, have a steady uptake of glucose by the tissues and the respiratory exchange ratio rises towards 1.0. However in patients with sepsis glucose uptake remains low and the respiratory exchange ratio fails to rise. On the other hand insulin levels show the same biphasic response, and NEFA concentrations the same fall, in both septic and control individuals. Thus although the pancreatic islets of the septic patients respond normally to glucose the insulin produced does not exert its normal effect and the septic patients may be described as "insulin resistant" 24

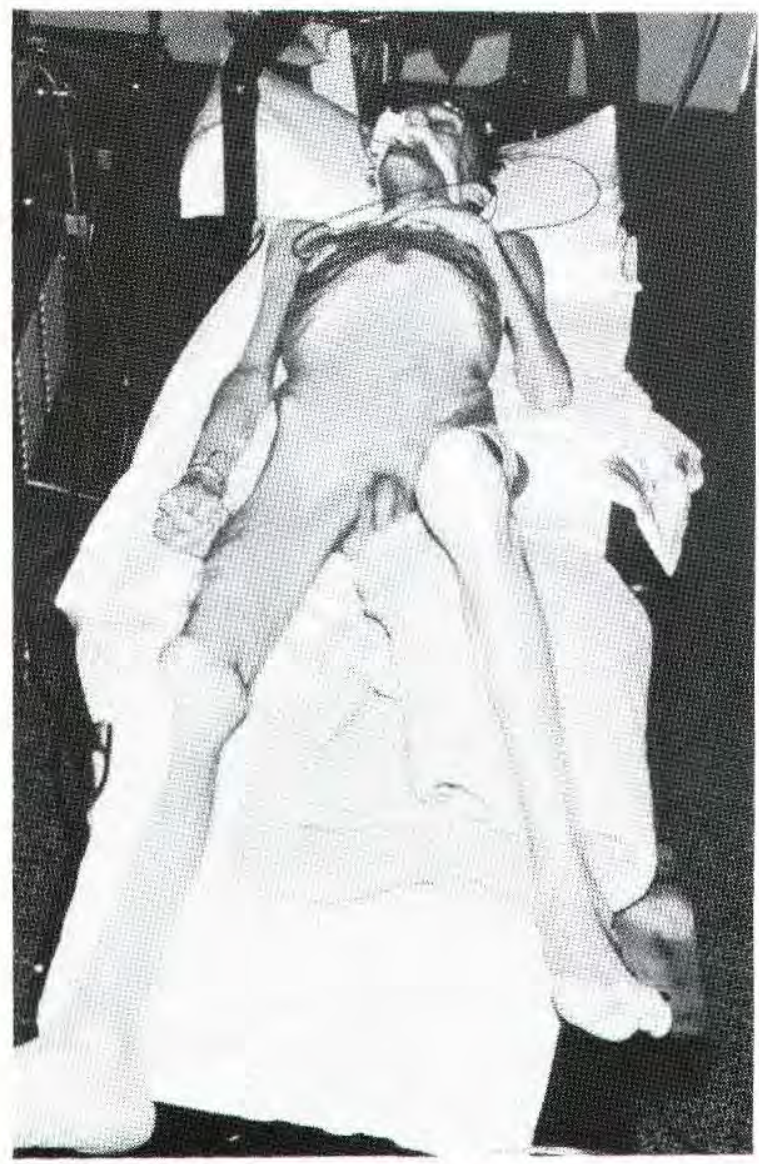

Fig 6. Gross cachexia due to prolonged intra-abdominal sepsis.

These findings have implications for the nutritional treatment of the septic patient for they imply that a proportion of the energy substrate should be given as fat, the morc septic the paticnt, the higher the proportion. There is however much more work to be done in this field before we completely understand and can control the metabolic and nutritional problems of the injured and septic patient.
It is clear to me that whilst all of us who practise surgery must be willing to adopt into surgical management the new materials and techniques that will come our way we must not abandon the lessons learned by our predecessors. In this respect we must regard such innovations in the same way as Trueti ${ }^{25}$ in his paper "Reflections on the past and present treatment of War wounds and fractures" which was published in 1976. Commenting upon the influence of penicillin, justifiably hailed as a major advance in this treatment of infections he stated.

"Its recognised efficiency during the first years of its use tended to have a retrograde effect upon wound management. A surgeon was inclined to rely more upon a substance that would kill germs than on the skill of his surgical techniques".

As I have shown in my talk today this message has always been proven to be correct and as far as I can sec will continue to be correct in years to come. It is up to us to see that future generations of military and civilian surgeons, whilst wisely using advances such as the newer generations of antibiotics, nutritional support, and other techniques yet to be developed, do not forget that theyc will never work without skilful and judicious excision ofo dead and infected tissues.

\section{REFERENCES}

1. Fraser 1. The Doctor's debt to the soldier. IR Army Med Corps 1972; 118: 60-75.

2. Mitchiner P H. Prognosis in carbuncle. Lancet 1935; i: 507.

3. MITCHINER P H. Some hints on prophylaxis, diagnosis and treatment of deep infections of the hand. Si Thomas Hospital Gazette, 1935; 35: 10-13.

4. Mitchiner P H. Infection of the face and lips. Practitioner 1936; 136: $367-375$

5. HUNTER J. Treatise on the blood, inflamation and gunshot wounds. London: Sherwood, Gilbert and Piper, 1928.

6. Barves J (Ed). The Medical and Surgical History of the War of the Rcbellion 1861-1865. Washington, Government Printing Office, Surgical volume.

7. BOWLBY D. British military surgery in the time of Hunter and the Great War. Lancet 1919: i: 285-290.

8. MitChiner P H. Immediate surgery in air raids. Practitioner 1939; 142: 197-206.

9. Heaton L D. Progress in Army Medicine. Medical Progress in World War II. Md State Med J 1960; 9: $433-438$

10. Leicester R J. The Falklands Experience. In: A Memorial to Sir Howard Florey. Viewpoint Publishing Ltd., 1985.

11. KRLKOWSKI $\mathrm{Z} \mathrm{H}$ et al. Infection after abdominal surgery: 5 year prospective study, $B r$ Med $J$ 1984; 288: $278-280$

12. KeIGHLEY M R. et al. Comparison between systemic and oral antimicrobial prophylaxis in colo-rectal surgery. Lancet 1979; i: 894-897. 
13. Strachan C. Antibiotic prophylaxis in "clean" surgical procedures. World J Surg 1982; 6: 273-280.

14. Aeberhart $\mathbf{P}$ and Casey $\mathbf{P}$ A. Reoperation for postoperative intra-abdominal sepsis. Huber, Berne, Switzerland: Huber, 1983.

15. Hudspeth A S. Radical surgical debridement in the treatment of advanced generalised bacterial peritonitis. Arch Surg 1975; 10: 1233-1266.

16. Polk H C and FRY D E. Radical peritoneal debridement for established peritonitis. The results of a prospective randomised controlled trial. Ann Surg 1980; 192: 350-355.

17. Fagniez P L et al. La laparostomie. Le Concours Medical $1979 ; 101$ : 4569-4573.

18. Mughal $\mathbf{M} \mathbf{M}$, Bancewicz $\mathbf{J}$ and Irving $\mathbf{M} \mathbf{H}$. "Laparostomy", a technique for the management of intractable intra-abdominal sepsis. Br $J$ Surg 1986; 73: $253-259$.
19. Mughal M M, Bancewicz J and IRving M H. The surgical management of pancreatic abscess. Ann $R$ Coll Surg Engl 1987; in press.

20. LEVY $\mathrm{E}$ et al. Le drainage actif prolonge des pancreatites aiguës necrotico-haemorragiques. Ann Chir 1984; 38: 351-356.

21. Elebute E A and Stoner H B. The grading of sepsis. $B r J$ Surg 1983; 70: 29-31.

22. STONER H B. et al. The effect of sepsis on the oxidation of carbohydrate and fat. BrJ Surg 1983; 70: 32-35.

23. Stoner H B. Metabolism after trauma and sepsis. Circ Shock 1986; 19: 75-87.

24. White $\mathbf{R}$ H et al. Glucose utilisation in septic surgical patients studied by the hyperglycaemic glucose clamp techique. Arch Emer Med 1984; 1: 191-192.

25. Trueta J. Reflections on the past and present treatment of war wounds and fractures. Milit Med 1976; 14: $255-258$.

\section{ACADEMIC ACHIEVEMENTS}

\author{
Master of Science (Community Medicine) \\ Fellowship of the Faculty of Occupational Medicine \\ Royal College of Physicians.
}

Fellowship of the Royal College of Radiologists

Fellowship of the Royal College of Surgeons of England

Fellowship of the Royal College of Surgeons of Edinburgh

\author{
Major J P Edmondson-Jones, RAMC \\ Brigadier I P Crawford, GM, L/RAMC \\ Major P Cory, RAMC \\ Major N D Raby, RAMC \\ Captain G R Ford, RAMC \\ Captain J D S McCutchan, RAMC
}

Major N A Johnson, RAMC 